\title{
Urban population looking for rural landscapes: Different appreciation patterns identified in Southern Europe
}

\author{
Mara Almeida, Isabel Loupa-Ramos, Helena Menezes, Sónia Carvalho-Ribeiro, Nuno \\ Guiomar, Teresa Pinto-Correia
}

\begin{abstract}
In the context of the peripheral European rural landscapes, the role of the urban population, generally referred to as the 'outsiders', has shown to be influential in the dynamics of rural space. This influence occurs namely through the demand for non-productive functions leading to the emergence of new modes of occupancy. In addition, the emerging policy framework concerning policies and planning in rural landscapes call for an improved understanding of the diversified social demands for these landscapes. We argue that a more profound knowledge on the urban demand for rural landscape is needed to better integrate the urban interests into rural policy and planning. The present paper aims to gain greater insight on this demand by identifying landscape preferences of urban users, framed by the multifunctional transition theory, and using a photo-based survey with contrasting land covers derived from CORINE Land Cover classes. Furthermore, the use of land cover classes as the main landscape component, and thereby relating preferences to specific land covers, offers a sound basis for a territorial approach, able to integrate landscape into rural policy and land use planning practice. A case-study in Southern Portugal was developed at the regional scale and results showed different appreciation patterns for rural landscapes varying from humanised and more naturalised landscapes according to the different functions sought by urban users. Another prominent result is that urban demand for rural landscapes, even if driven by consumption, is strongly influenced by both protection and production values. A deeper knowledge on the interests of urban population can be a step forward for rural communities, land managers, and sectoral policy decision-makers to better define investment strategies in rural-urban partnerships facing the growing urban demand over rural space.
\end{abstract}

Keywords: Rural landscape; Urban population; Landscape preferences; Land cover; Regional policy; Alentejo region

Doi: $\underline{10.1016 / j . l a n d u s e p o l .2015 .09 .025}$

Citação: Almeida, M., et al, 2015, Urban population looking for rural landscapes: Different appreciation patterns identified in Southern Europe, Land Use Policy, Available online 9 October 2015, Doi: 10.1016/j.landusepol.2015.09.025 